\title{
Microbiologically Induced Corrosion of X80 Pipeline Steel in a Near-Neutral pH Soil Solution
}

\author{
Tang-Qing Wu $\cdot$ Mao-Cheng Yan $\cdot$ De-Chun Zeng $\cdot$ Jin Xu $\cdot$ Chang-Kun Yu $\cdot$ Cheng Sun $\cdot$ Wei Ke
}

Received: 8 April 2014/Revised: 26 August 2014/Published online: 21 November 2014

(C) The Chinese Society for Metals and Springer-Verlag Berlin Heidelberg 2014

\begin{abstract}
MIC of X80 pipeline steel in a near-neutral pH soil solution in the presence and absence of sulfate-reducing bacteria (SRB) was monitored by electrochemical techniques and microbiological tests. The results show that soil solution is more close to the complex soil environment around pipeline. The activity of SRB leads to the shift of the phase response to low frequency, the decrease of electrolyte resistance and the alteration of dielectric constant of the film. Both the activity and metabolite of SRB influence the corrosion behavior of the steel. The steel surface undergoes localized attack in the SRB-inoculated soil solution, whereas only slight uniform corrosion occurs in the sterile soil solution.
\end{abstract}

\section{KEY WORDS: Sulfate-reducing bacteria; Pipeline steel X80; Electrochemical impedance spectroscopy} (EIS); Scanning electron microscopy

\section{Introduction}

For the security and economy reasons, high-strength steel pipeline is regarded as the most cost-effective way for oil and natural gas transportation [1]. Recently, high-strength pipeline steel (API 5L X80 and above) has been developed and used in the pipeline projects in the northern Canada, the Japanese Sub-Sea [2], and the west-east gas transportation project in China [3, 4]. Microbiologically induced corrosion (MIC) by sulfate-reducing bacteria (SRB) has

Available online at http://link.springer.com/journal/40195

T.-Q. Wu · M.-C. Yan · J. Xu · C.-K. Yu · C. Sun $(\bowtie) \cdot$ W. Ke Environmental Corrosion Center, Institute of Metal Research, Chinese Academy of Sciences, Shenyang 110016, China

e-mail: chengsun@imr.ac.cn

T.-Q. $\mathrm{Wu}$

School of Materials Science and Engineering, Xiangtan

University, Xiangtan 411105, China

D.-C. Zeng

Oil-Gas Storage and Transportation Company of Xinjiang

Oilfield Branch, Karamay 834002, China been regarded as one of the most common problems of underground pipelines $[5,6]$ since it was firstly observed in 1926 [7].

Several mechanisms have been proposed to explain the role of SRB in corrosion processes of steels, iron, and alloys [8]. The cathodic depolarization theory has been widely accepted for MIC by SRB, which emphasizes the role of the sulfate-reducing process by SRB in removing hydrogen from the steel surface and increasing the cathodic current [9]. The metal sulfide by the activity of SRB can stimulate localized corrosion by acting as cathodes to the steel substrate, even in the absence of hydrogen sulfide, which forms the foundation of the galvanic cell theory [10, 11]. Beech and Cheung believed that the Fe-containing extracellular polymer substance (EPS) has a beneficial effect on promoting the corrosion process in 1995 [12]. The sulfate-reducing reaction is almost involved in all the mechanisms. Recently, direct electron transfer (DET) from carbon steel to electrically active SRB has attracted our attention $[13,14]$ since extracellular microbial nanowires were found in 2005 [15]. SRB can acquire the energy needed by capturing atomic hydrogen from the steel surface or by obtaining electrons via direct or indirect contact 
with the steel substrate [16]. And the DET from carbon steel to the electrically active SRB may be responsible for localized corrosion of the carbon steel in the presence of SRB [16, 17].

Corrosion inhibition effects of SRB in the presence of biofilm are also reported [18]. In most cases, the inhibition effect comes from the living bacteria. The biofilm of SRB was found to block against the entry of harmful chloride, inhibiting the pitting of the stainless steel [19]. The negative charge of the bacteria and the EPS on the steel surface are useful for repelling the entry of chloride ions [20, 21]. The carboxylate functional groups within the extracellular polysaccharides by SRB have a buffering capacity [19], which could hinder the acidification of the solution underneath the biofilm. We have found that corrosion rate of a mile steel is lower in the SRB-inoculated soil solution than that in the sterile soil solution in the early experimental period when large amounts of SRB aggregate on the steel surface [22].

Most of the researches investigate SRB-induced corrosion in culture-media, however, the underground soil environments around pipeline are more complex. In the present paper, the effect of SRB on electrochemical behavior of API X80 pipeline steel was investigated by electrochemical techniques during various growth phases of SRB in a near-neutral soil solution. The evolution of the biofilm and its effect on the corrosion process were discussed.

\section{Materials and Methods}

\subsection{Material}

Material used in this study was an API X80 pipeline steel, with chemical composition (wt\%) given in Table 1. A typical metallographic graph is presented in Fig. 1, showing the ferrite structure of the X80 steel. The specimens $(10 \mathrm{~mm} \times 10 \mathrm{~mm} \times 3 \mathrm{~mm})$ were machined and embedded in epoxy resin, leaving an area of $10 \mathrm{~mm} \times 10 \mathrm{~mm}$ for electrochemical measurements. The work surface of the specimens was mechanically abraded according to the national standards GB5776-86 with a series of grit papers (No. 400, No. 600, No. 800, and No. 1000), and then cleaned successively in acetone and alcohol. All the prepared specimens were sterilized under ultraviolet ray for $30 \mathrm{~min}$ prior to the experiment.

\subsection{Soil Solution and Microorganisms}

A meadow soil collected in Shenyang, China $\left(41^{\circ} 45^{\prime}\right.$ $48.31^{\prime \prime} \mathrm{N}, 123^{\circ} 27^{\prime} 11.12^{\prime \prime} \mathrm{E}$ ) was used in this work, the $\mathrm{pH}$ value of it is 7.75 . The composition of the soil is given in
Table 1 Chemical compositions of X80 pipeline steel (wt\%)

\begin{tabular}{llllllll}
\hline $\mathrm{C}$ & $\mathrm{Mn}$ & $\mathrm{Si}$ & $\mathrm{P}$ & $\mathrm{S}$ & $\mathrm{Mo}$ & $\mathrm{Ni}$ & $\mathrm{Cr}$ \\
\hline 0.07 & 1.82 & 0.19 & 0.007 & 0.023 & 0.010 & 0.17 & 0.026 \\
\hline $\mathrm{Cu}$ & $\mathrm{V}$ & $\mathrm{Nb}$ & $\mathrm{Ti}$ & $\mathrm{Al}$ & $\mathrm{N}$ & $\mathrm{B}$ & $\mathrm{Fe}$ \\
\hline 0.020 & 0.002 & 0.056 & 0.012 & 0.028 & 0.004 & 0.0001 & Bal. \\
\hline
\end{tabular}

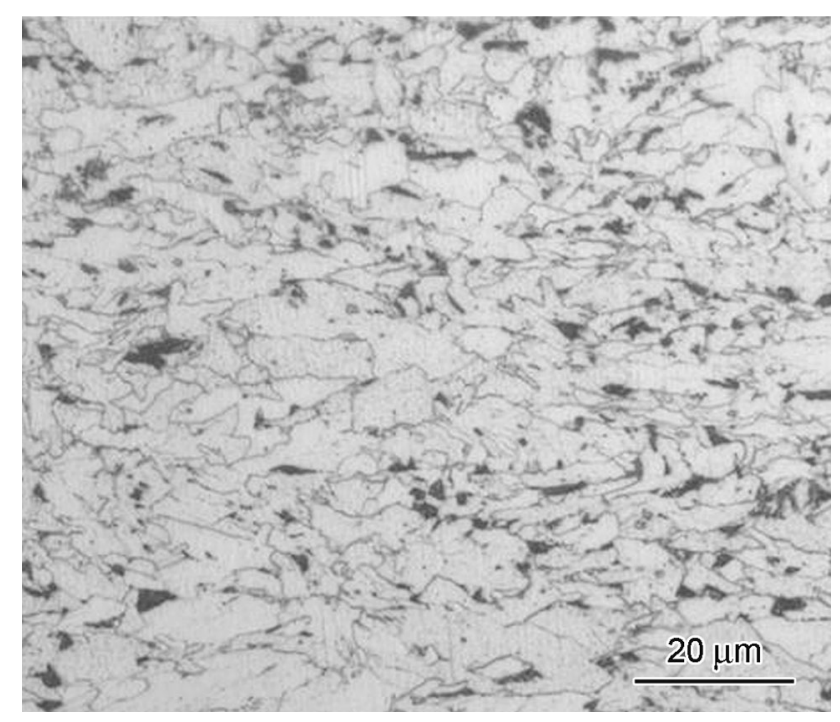

Fig. 1 Microstructure of X80 pipeline steel

Table 2. The soils were dried at $105{ }^{\circ} \mathrm{C}$ for about $10 \mathrm{~h}$, and then ground by a lapping machine, and passed through a sieve with 1-mm-diameter openings. The soil solution was prepared by filtering the solution with the water/soil ratio of $1: 1$. The soil solution was autoclaved at $121{ }^{\circ} \mathrm{C}$ for $20 \mathrm{~min}$ and stored at $4{ }^{\circ} \mathrm{C}$ for use.

The API RP-38 medium used in this investigation was composed of $\mathrm{MgSO}_{4} \cdot 7 \mathrm{H}_{2} \mathrm{O}(0.2 \mathrm{~g} / \mathrm{L}), \mathrm{KH}_{2} \mathrm{PO}_{4}(0.5 \mathrm{~g} / \mathrm{L})$, $\mathrm{NaCl}(10.0 \mathrm{~g} / \mathrm{L})$, ascorbic acid $(1.0 \mathrm{~g} / \mathrm{L})$, sodium lactate $(4.0 \mathrm{~g} / \mathrm{L})$, yeast extract $(1.0 \mathrm{~g} / \mathrm{L})$, and $\mathrm{Fe}\left(\mathrm{NH}_{4}\right)_{2}\left(\mathrm{SO}_{4}\right)_{2}$ $(0.02 \mathrm{~g} / \mathrm{L})$. The $\mathrm{pH}$ value of the culture solution was regulated between 7.0 and 7.2 by $1 \mathrm{~mol} / \mathrm{L} \mathrm{NaOH}$. The same SRB strain (desulfovibrio desulfuricans) was used as described in previous paper [23]. Prior to the experiment, SRB strains were activated in an incubator for $12 \mathrm{~h}$, and then $50 \mathrm{~mL}$ of SRB strains was subsequently transferred into individual aliquots of $950 \mathrm{~mL}$ sterile soil solution. Before the transfer, pure nitrogen was bubbled through the sterile soil solution about $2 \mathrm{~h}$. The abraded specimens were hung in the SRB-inoculated soil solution in a sealed jar for corrosion experiments. For the sterile environment, $50 \mathrm{~mL}$ medium was transferred into $950 \mathrm{~mL}$ sterile soil solution.

SRB number was determined by the three-tube multiple most probable number (MPN) method according to the 
Table 2 Composition of the used soil (wt $\%$ )

\begin{tabular}{llllllllllll}
\hline Soil type & $\mathrm{NO}_{3}^{-}$ & $\mathrm{Cl}^{-}$ & $\mathrm{SO}_{4}^{2-}$ & $\mathrm{HCO}_{3}^{-}$ & $\mathrm{Ca}^{2+}$ & $\mathrm{Mg}^{2+}$ & $\mathrm{K}^{+}$ & $\mathrm{Na}^{+}$ & Organics & Total nitrogen & Total salt \\
\hline Meadow soil & 0.0046 & 0.0031 & 0.0048 & 0.0234 & 0.0057 & 0.0032 & 0.0002 & 0.0014 & 2.26 & 0.091 & 0.0464 \\
\hline
\end{tabular}

American Society of Testing Materials (ASTM) Standard D4412-84. The $\left[\mathrm{SO}_{4}^{2-}\right]$ of bulk solution was determined with time by UV spectrophotometer (Shanghai YOUKE Instrument and Meter Co., Ltd).

\subsection{Electrochemical Analysis}

The electrochemical properties of the corroded surface immersed in the soil solutions were investigated by open circuit potential (OCP) and electrochemical impedance spectroscopy (EIS). All experiments were performed in a three-electrode electrochemical cell, with a platinum electrode used as the counter electrode, and a saturated calomel electrode (SCE) as the reference electrode. The tests were operated using an EG\&G PARSTAT2273 electrochemical measurement system manufactured. The frequency range was from $1 \mathrm{mHz}$ to $100 \mathrm{kHz}$ and the amplitude of the sinusoidal voltage signal was $10 \mathrm{mV}$.

\subsection{Analysis of Corrosion Products}

After the experiment, the appearance of X80 pipeline steel in the soil solutions was visualized after preparation using the following procedures. The exposed surface of the samples was cleaned in $100 \%$ alcohol for ten minutes, followed by drying in a cold air flow, and storing in an oxygen-free desiccator. The morphologies of both corrosion products and the corroded surface were obtained by a scanning electron microscope. Prior to the corroded surface examination, the corrosion products or biofilms on the steel surface were removed using a rust remover solution composed of water $(100 \mathrm{~mL}), \mathrm{HCl}(3 \mathrm{~mL})$, and cis-2-butan-1, 4-diol (4 mL).

\section{Results and Discussion}

\subsection{Characteristics of SRB Growth and Variation of Environment}

The growth curve of SRB as a function of time is shown in Fig. 2. After several hours of adjustment, the number of the planktonic SRB rapidly increases to $2.0 \times 10^{7} \mathrm{cell} / \mathrm{mL}$ at the end of the third day from $1.5 \times 10^{4}$ cell $/ \mathrm{mL}$ on the first day. However, the number of SRB decreases quickly, to $1.0 \times 10^{2}$ cell $/ \mathrm{mL}$ on the 20 th day, and then remains stable. The results are in agreement with our previous study

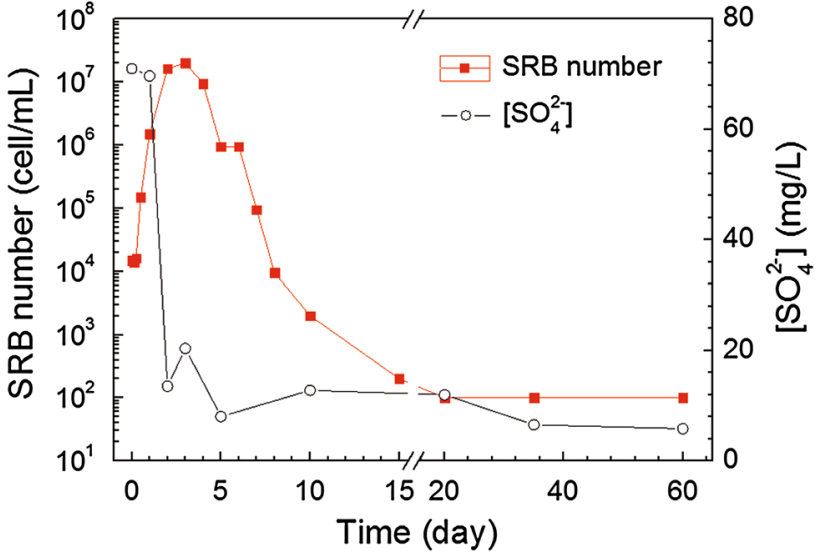

Fig. 2 Growth curve of $\mathrm{SRB}$ and variation of $\left[\mathrm{SO}_{4}^{2-}\right]$ during the experiment

[22]. Prior to the experiment, pure nitrogen was bubbled through the soil solutions, leaving a limited oxygen concentration in the soil solutions. Once the pipeline steel is immersed in soil solution, the oxygen concentrations in soil solution also begin to decrease with time, because the cathodic reaction for corrosion of the steel in neutral solutions is oxygen-absorption. In the anaerobic environment with high organic content (Table 2), the planktonic SRB experiences a rapid growth during the first 3 days. From the 4th day to the 20th day, since the nutrition in soil solution is gradually used up, the number of SRB decreases sequentially, after that SRB is in the declining period.

The variation of $\left[\mathrm{SO}_{4}^{2-}\right]$ with time is also measured and listed in Fig. 2. The SRB growth can be confirmed by the variation of $\left[\mathrm{SO}_{4}^{2-}\right]$. $\left[\mathrm{SO}_{4}^{2-}\right]$ decreases sharply as the number of SRB increases quickly, then remains stable at a low number. It shows that $\mathrm{SRB}$ consumes $\left[\mathrm{SO}_{4}^{2-}\right]$, and $\left[\mathrm{SO}_{4}^{2-}\right]$ decreases fast during the cellular exponential growth phase. The activity of SRB leads to a sharp decrease of $\left[\mathrm{SO}_{4}^{2-}\right]$ of the soil solution.

According to the cathode depolarization theory proposed [9], the following reaction occurs during the metabolic process of SRB in a near-neutral $\mathrm{pH}$ environment:

$4 \mathrm{Fe}+\mathrm{SO}_{4}^{2-}+4 \mathrm{H}_{2} \mathrm{O} \rightarrow \mathrm{FeS}+3 \mathrm{Fe}(\mathrm{OH})_{2}+2 \mathrm{OH}^{-}$.

Due to the activity of $\mathrm{SRB}, \mathrm{SO}_{4}^{2-}$ is consumed and its concentration might decrease over time.

As represented in reaction (1), the dissolved sulfide level in the SRB-inoculated environment may increase sharply 
with the quick decrease of sulfate during the cellular exponential growth phase (Fig. 2). Alabbas et al. found that the level of dissolved sulfide increased drastically in the first 12 days and remained stable until the 20th day in a biotic growth medium [17]. However, in this experiment, the sulfate has almost been used up in the first 3 days. Kuang et al. have displayed that in a seawater system the concentration of the sulfide increases with increasing SRB number during the exponential phase and reaches the maximum value when the SRB number achieves the maximum value at the 4th day [24]. The duration discrepancy of the sulfate consuming (or the sulfide produce in references [17] and [24]) may arise from the difference of the tested SRB growth medium. $\left[\mathrm{SO}_{4}^{2-}\right]$ in the Baar's medium used in AlAbbas' paper [17] is more than $3 \mathrm{~g} / \mathrm{L}$, almost 30 times higher than that in the soil solution used in this experiment (Fig. 2). Due to the adequate nutrition, the cellular exponential growth phase can keep a much longer time for their study than this experiment, and that the number of SRB in their study may be far larger. It is generally recognized that artificial seawater mixtures do not approximate the complexity of natural seawater, especially the organic material [25]. So, we believe that soil solutions are more close to the complex soil environment around pipelines.

\subsection{SEM and EDXA Analysis}

The micrographs of the corrosion products of the steel after 60 days exposure in the sterile and SRB-inoculated soil solutions are shown in Fig. 3. In the sterile soil solution, as shown in Fig. 3a and b, the steel surface is covered with a dense film of the corrosion products. The Corrosion product is evenly uniform and just like pine bark. The EDXA results show that the corrosion products are iron oxides (Table 3). Besides, $\mathrm{Cr}$ and $\mathrm{Mn}$ in the API 5L X80 steel are observed in the corrosion products. However, there is no intact film but much sediment observed on the steel surface in the SRB-inoculated soil solution (Fig. 3c). S detected in the sediment may be the metabolize products or extracellular polymer by the activity of SRB. $\mathrm{Ca}$ and $\mathrm{Si}$ are observed in the sediment, which is the deposit of soil particle in the soil solution. As indicted by Fig. 3d, some irregularly ruptured thin membranes are observed at some place. At these positions, elements including $\mathrm{S}$ and $\mathrm{P}$ are also detected by EDXA (Table 3), indicating that these are the mixture of the ruptured biofilm and the deposit of the soil particle exist. In the SRB-inoculated soil solution, polishing scratches can be seen on the steel surface (marked by black arrows in Fig. 3c), which indicates that no favorable film formed on the surface in the later stage of the experiment.
The corrosion products in the sterile and SRB-inoculated soil solutions have different morphologies and compositions (Fig. 3; Table 3). Sulfide forms via reaction (1), and then it deposits on corrosion product or it is wrapped into the corrosion product film in the SRB-inoculated environment. The biofilm on the steel surface tends to rupture or detach in the SRB-inoculated system in the later stage of the experiment. The corrosion products in the sterile soil solution are continuous, while in the SRBinoculated environment they are patched and ruptured. It is strange that $\mathrm{Ca}$ and $\mathrm{Si}$ are detected on the steel substrates in the SRB-inoculated environment but not in the sterile soil solution. It is likely to be because $\mathrm{Ca}$ and $\mathrm{Si}$ were wrapped in EPS in the SRB-inoculated environment, while they only deposited on the surface of the dense product layer and was washed away by alcohol during the cleaning process in the sterile medium.

Corroded appearances of the steel surface, after removing corrosion products, are shown in Fig. 4. In the sterile soil solution, the corroded surface of the steel is rough and only slight localized corrosion can be observed (Fig. 4a), indicating that the uniform corrosion dominates the corrosion attack. In the SRB-inoculated soil solution (Fig. 4b), the corroded surface is, in general, smoother than that in the sterile environment. But some shallow localized pittings ( $30 \mu \mathrm{m}$ in diameter) are observed on the corroded surface. The fact indicated the corrosion taking place in the SRB-inoculated environment is the localized corrosion rather than the uniform corrosion.

In the sterile soil solution, a large number of corrosion products accumulate on the surface of the steel and form a dense film on the surface as shown in Fig. 3a and b. The film separates the steel from the corrosive environment and impedes the diffusion of corrosive ion from the bold solution inside the steel interface, e.g., $\mathrm{Cl}^{-}$and $\mathrm{SO}_{4}^{2-}$. Besides, the film evenly distributes on the surface. Thus, there is no segregation phenomenon happening on the surface, although the microstructure of the steel was uneven (some discrete inclusion and loosen were found in Fig. 1). Therefore, the steel surface in the sterile system only experiences uniform corrosion. However, the metabolic activity of SRB and the evolution of biofilm are responsible for the corrosion process taking place on the steel in the SRB-inoculated soil solution. As shown in Fig. $3 \mathrm{c}$ and d, the loose, discrete deposit and the ruptured film attache to the coupon, forming a porous biofilm on the surface of the steel. This porous biofilm not only entraps deleterious metabolites secreted by bacteria, but also alters and influences the immediate surroundings of the metal surface [26], and even forms microcells on the surface [10, 11], resulting in localized corrosion of the steel. The presence of SRB facilitates the formation of the ferrous sulfide 

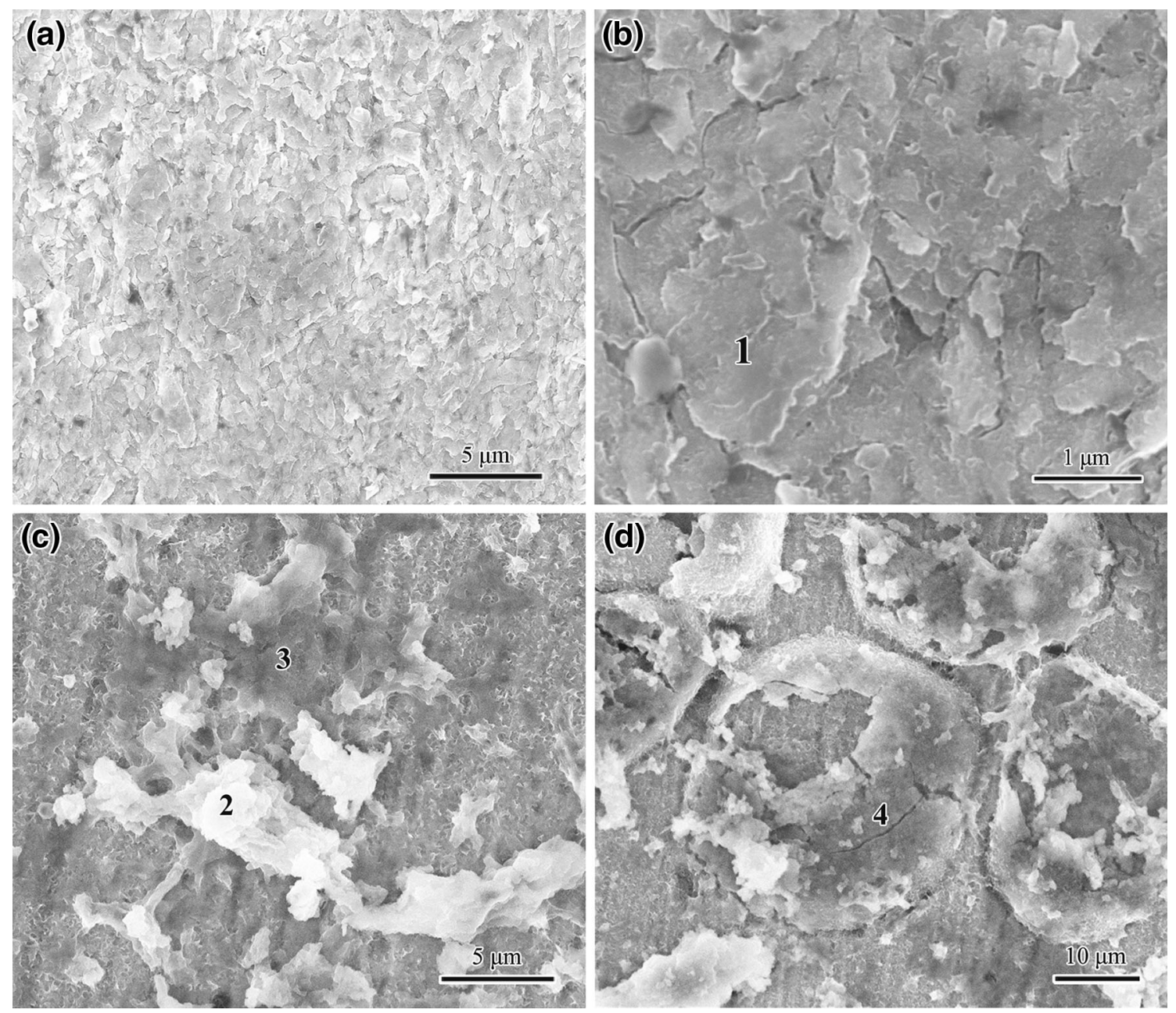

Fig. 3 Microscopic appearance of the surface of X80 pipeline steel in soil solution after 60 days: a sterile, b partial enlargement of Fig. 8 a, c, d inoculated

by reaction (1) and the sedimentation of the ferrous sulfide on the surface of the coupon (Table 3) [27]. The reduced sulfur compounds (ferrous sulfide) thus enhance localized corrosion by inducing pitting corrosion [26]. Beyond that, SRB can acquire energy by taking up cathodic hydrogen from the steel or by obtaining electrons through direct or indirect contact with steel [13-17], which is also one of the reasons for localized corrosion.

\subsection{Electrochemical Measurements}

The open circuit potential $\left(E_{\text {corr }}\right)$ in Fig. 5 indicates different tendencies in the sterile and SRB-inoculated environments. $E_{\text {corr }}$ decreases quickly during the first 3 days in the two environments, while $E_{\text {corr }}$ in the SRB-inoculated soil solution decreases lower than that in the sterile soil solution. Then, $E_{\text {corr }}$ in the SRB-inoculated soil solution ennobles from $-770 \mathrm{mV}$ on the 2 nd day to $-740 \mathrm{mV}$ after 30 days. However, in the sterile soil solution, $E_{\text {corr }}$ fluctuates slightly from the 2nd day to the end of the experiment. $E_{\text {corr }}$ in the SRB-inoculated environments is typically $20 \mathrm{mV}$ lower than that in the sterile soil solution in the first 5 days of the experiment.

The decrease of $E_{\text {corr }}$ in the first 3 days is associated with the chemical and electrochemical equilibrium process on the steel surface in the environments. More negative $E_{\text {corr }}$ values have been observed by many researchers in the presence of bacteria in different systems [28-32]. It is generally recognized that this phenomenon could result from the establishment of biofilm, metabolic processes of $\mathrm{SRB}$, or establishment of a cathodic reaction whose reversible potential was low [29].

EIS, as a non-destructive electrochemical technique, has been widely used to investigate the electrochemical properties of the corroded surface [30]. The Nyquist and Bode plots of the steel in the sterile soil solution are shown in Fig. 6. In the sterile soil solution, the impedances in the first 5 days are smaller than that in the rest time (Fig. 6a, 
Table 3 Results of EDXA in the different positions on the surface of X80 pipeline steel in the soil solutions after 60 days (at\%)

\begin{tabular}{llllllllll}
\hline Position & $\mathrm{C}$ & $\mathrm{O}$ & $\mathrm{Fe}$ & $\mathrm{S}$ & $\mathrm{P}$ & $\mathrm{Si}$ & $\mathrm{Ca}$ & $\mathrm{Cr}$ & $\mathrm{Mn}$ \\
\hline 1 & 23.34 & 7.29 & 67.62 & - & - & - & - & 0.36 & 1.19 \\
2 & 54.43 & 22.68 & 11.63 & 10.81 & - & 0.15 & 0.31 & - & - \\
3 & 41.07 & 27.24 & 18.21 & 13.02 & - & - & 0.46 & - & - \\
4 & 34.77 & 29.45 & 26.00 & 7.24 & 0.76 & 0.40 & 0.94 & - & 0.43 \\
\hline
\end{tabular}
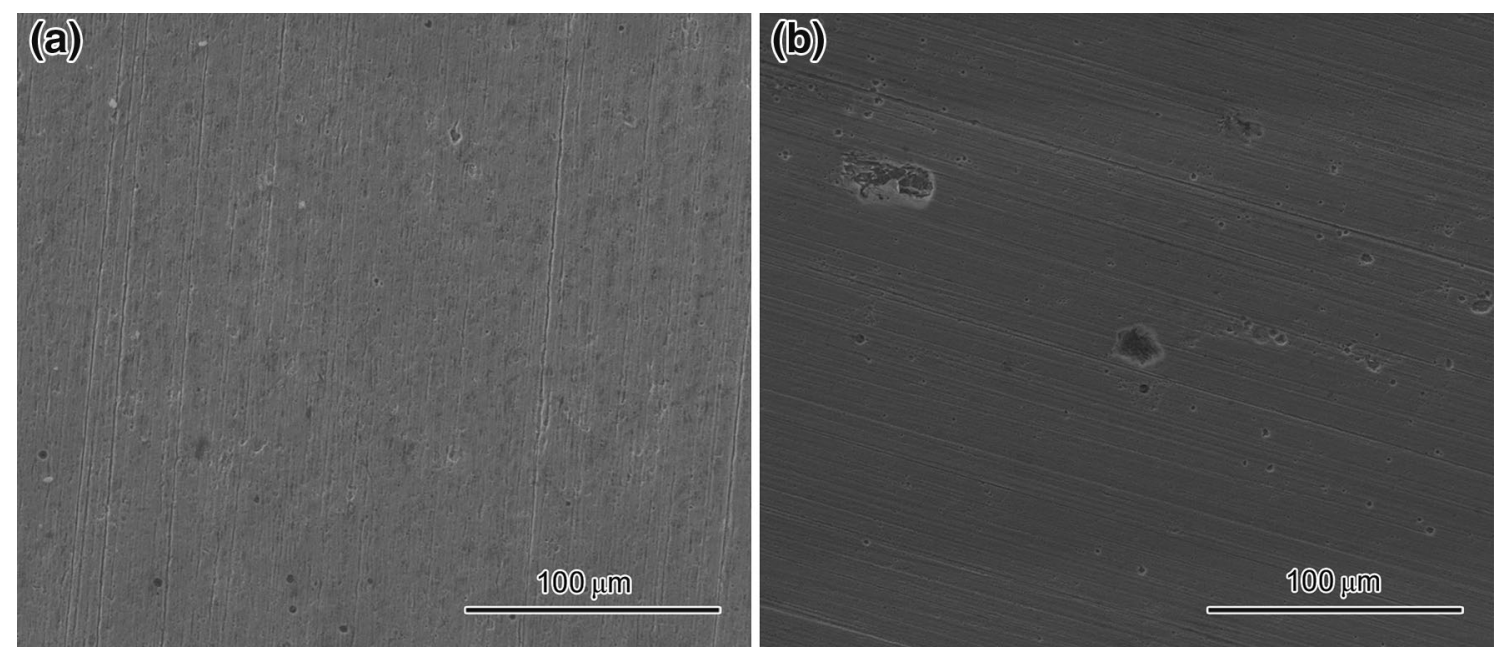

Fig. 4 Microscopic appearance of surface of X80 pipeline steel in soil solution after removing corrosion products: a sterile, $\mathbf{b}$ inoculated

b), indicating the decrement of the corrosion rate of the steel in this environment with time. The impedance at the highest frequency in the sterile soil solution has a little change in the whole experiment (Fig. 6b). Besides, on the 1st day, a Weber impedance loop can be observed in Bode plots (Fig. 6c), and the frequency corresponding to the highest phase moves slowly to the low frequency during the experiment process. However, as shown in Fig. 7, in the SRB-inoculated soil solution, the impedances at the lowest frequency go downhill quickly after 5 days and the impedance at the high frequency also decreases over time (Fig. 7a, b). Besides, the frequency corresponding the highest phase experiences a shift to low frequency in the 5 th day of this experiment in the SRB-inoculated soil solution.

The EIS data for the steel in the sterile and SRB-inoculated soil solutions show a significant differences in the time constant, the impedance response (at the lowest and highest frequencies), and the phase response (Figs. 6, 7) [17]. The Weber impedance loop in the first day in the sterile environment is due to the diffusion behavior of the solution. The impedance at high frequency is related to the electrolyte resistance $R_{\mathrm{S}}$ [33]. $R_{\mathrm{S}}$ decreases due to the variation of electrical conductivity of the SRB-inoculated soil solution. In the SRB-inoculated soil solution, hydrogen sulfide produced by SRB activities will react with ferrous iron to give sulfides. This product has high electrical

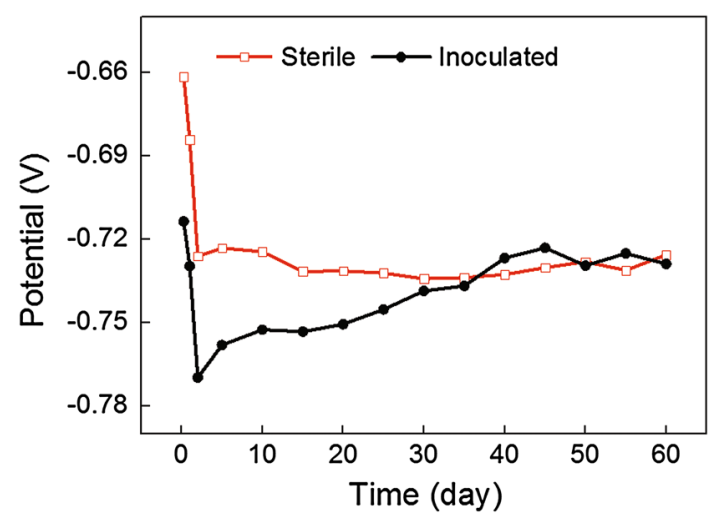

Fig. 5 Open circuit potential of X80 pipeline steel in the inoculated and the sterile soil solutions

conductivity [34], which sharply increases the electrical conductivity of the SRB-inoculated soil solution. Therefore, the electrolyte resistances $R_{\mathrm{S}}$ in the SRB-inoculated soil solution are lower and decrease faster than that in the sterile soil solution. The phase shift to low frequency reveals a higher electrical capacitance value [17], which is parallel to $R_{\mathrm{s}}$ results.

According to Yu et al. [14]., for carbon steel in the SRBinoculated medium, the contribution of corrosion product layer and SRB biofilm could not be separated. The same electrical circuit in Fig. 8a was used to study the corrosion 
(a)

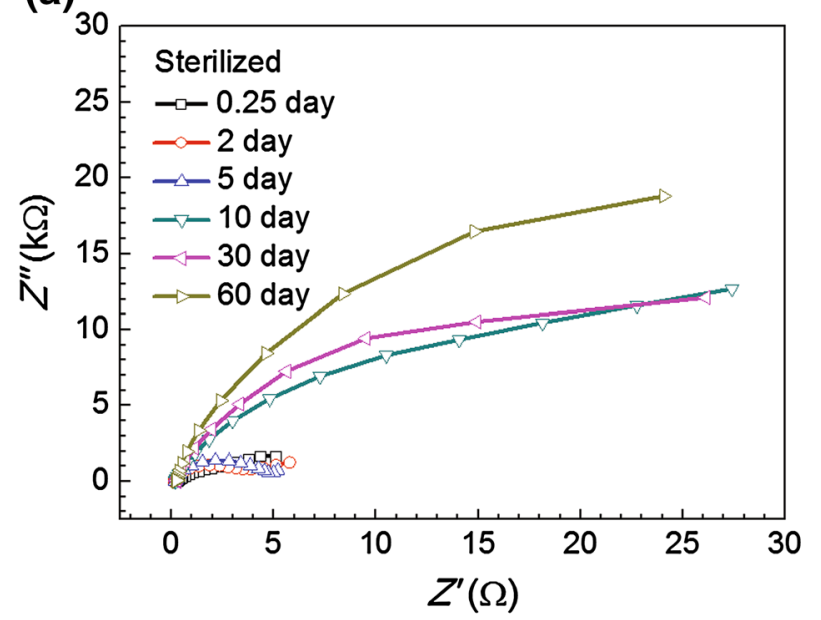

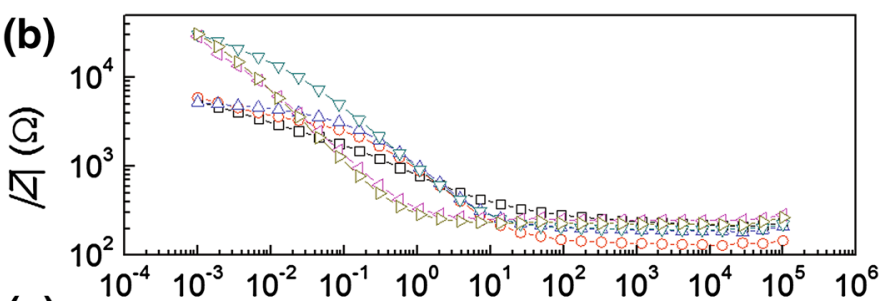

(c)

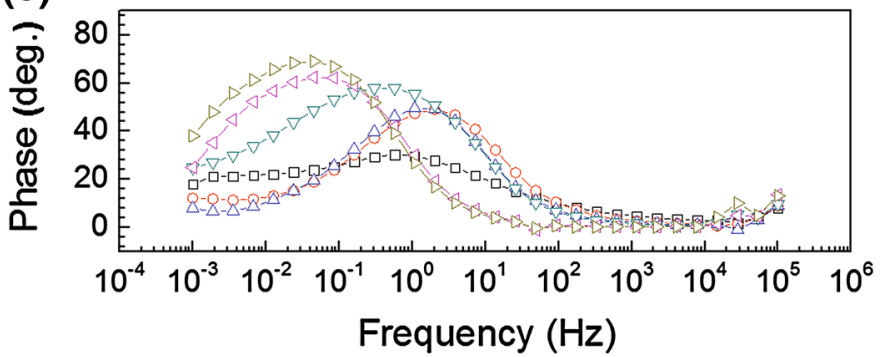

Fig. 6 Nyquist and Bode plots of X80 pipeline steel in the sterile soil solution

process in the sterile and SRB-inoculated environments. On the 1st day, fresh X80 steel coupons had no corrosion product on the surface, and a Weber impedance loop is detected in the sterile environment. Therefore, electrical simulative circuits shown in Fig. $8 \mathrm{~b}$ and $\mathrm{c}$ were used to fit the EIS data in the sterile and SRB-inoculated environment in the first day, respectively. In the circuit models, $R_{\mathrm{S}}$ represents an electrolyte resistance. $R_{\mathrm{f}}$ and $Q_{\mathrm{f}}$ represent a resistance and a capacitance of the film, respectively. $R_{\mathrm{ct}}$ and $Q_{\mathrm{d} 1}$ represent charge transfer resistance and a double layer capacitance, respectively. $O$ represents the Weber impedance. The fitting results are listed in Tables 4 and 5 .

Important information about the corrosion product layer and the biofilm can be obtained from the fitting results. As shown in Table 4 , in the sterile environment, $R_{\mathrm{f}}$ increases over time and $Y_{\mathrm{f}}$ remains roughly the same. The fact reveals that the corrosion product layer on the coupon gets thicker with time, but its conductivity keeps constant. However, in the SRB-inoculated environment, $R_{\mathrm{f}}$ declines while $Y_{\mathrm{f}}$ increases on the fifth day, as displayed in Table 5 . The decrease of $R_{\mathrm{f}}$ arises from the activity of SRB. The increase of $Y_{\mathrm{f}}$ is associated with the conductive iron sulfide [17] and the direct consumption of electrons from the steel by bacteria [15]. As for $R_{\mathrm{ct}}$, its value in the SRB-inoculated environment is bigger in the first 5 days and smaller in the next days than that in the sterile environment. The fact will be discussed in next section.

\subsection{Effects of SRB on Corrosion Process}

The resistance of the steel at low frequencies (e.g., less than $10 \mathrm{mHz}$ ) is relative to the polarization impedance $\left(R_{\mathrm{p}}\right)$, while that at high frequencies (e.g., more than $10 \mathrm{kHz})$ is related to the electrolyte resistance $\left(R_{\mathrm{s}}\right)$ [33].
The former reflects the corrosion reaction of the steel and is inversely proportional to the corrosion current [17] and hence to corrosion rate. The latter represents the electrolyte resistance of the soil solution, and the impedance at $10 \mathrm{kHz}$ is included in the impedance at $10 \mathrm{mHz}$ [33]. In this experiment, the polarization impedance $\left(R_{\mathrm{p}}, \Omega \mathrm{cm}^{2}\right)$ of the steel was calculated by Eq. (2)

$R_{\mathrm{p}}=|R|_{0.001 \mathrm{~Hz}}-|R|_{10 \mathrm{kHz}}$,

where $|R|_{0.001 \mathrm{~Hz}}\left(\Omega \mathrm{cm}^{2}\right)$ and $|R|_{10 \mathrm{kHz}}\left(\Omega \mathrm{cm}^{2}\right)$ are the impedance at $1 \mathrm{mHz}$ and the impedance at $10 \mathrm{kHz}$, respectively. Then, the corrosion current density $(\mathrm{mA} \mathrm{cm})^{2}$ and corrosion rate (CR, mpy) were obtained as follows [33]:

$i_{\text {corr }}=\frac{B}{R_{\mathrm{P}}}$,

$\mathrm{CR}=452.4 \frac{B}{R_{\mathrm{P}}}$,

where $B(\mathrm{mV})$ is a empirical constant and is fixed at $26 \mathrm{mV}$ in this experiment. This approach can simply extract some corrosion kinetic parameters without rigorous analysis of EIS data and has been accepted and widely used in the literature $[33,35,36]$.

The corrosion rates of the steel as a function of time are displayed in Fig. 9. In the early stage of this experiment (the first 5 days), corrosion rate of the steel in the SRB-inoculated soil solution is lower than that in the sterile environment, which is well consistent with the data from Bode plots (Figs. 6b, 7b) and $R_{\mathrm{ct}}$ (Tables 4, 5). The results show that corrosion of the steel is inhibited by SRB in the early stage of the experiment. The protective effects at the early stage may arise from iron sulfide and electronegativity of the biofilm. $\mathrm{FeS}$ formed inside the biofilm pores may generate cluster 
(a)

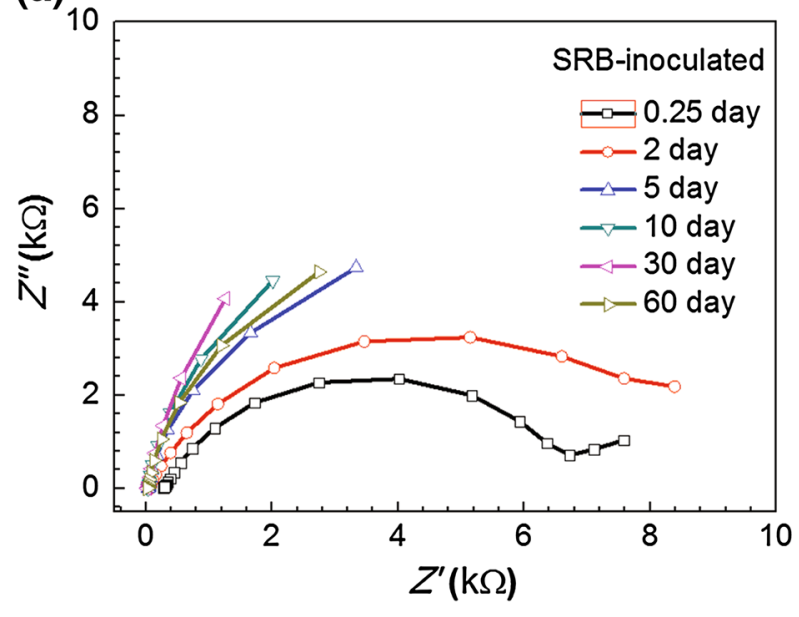

(b)

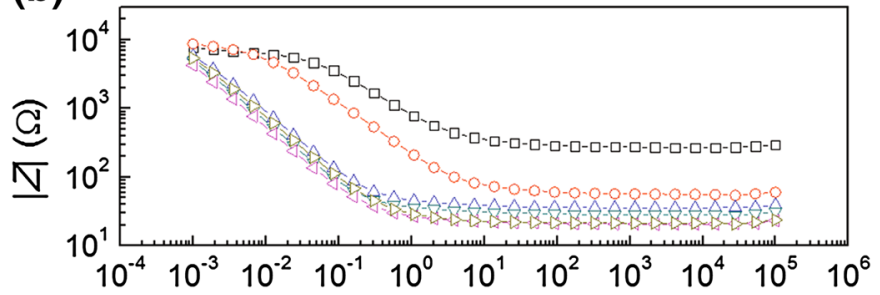

(c)

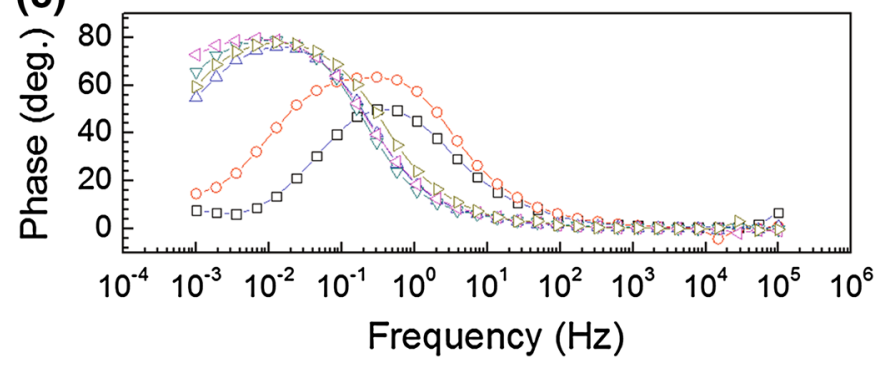

Fig. 7 Nyquist and Bode plots of X80 pipeline steel in the inoculated soil solution

(a)

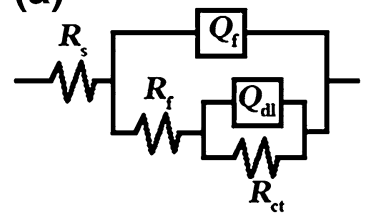

(b)

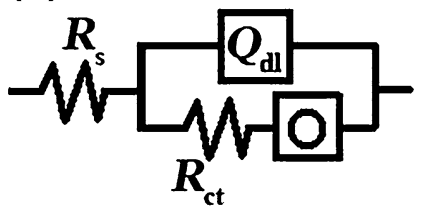

(c)

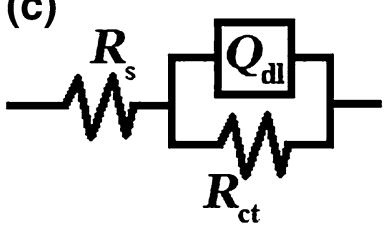

Fig. 8 Circuits models used to fit EIS data: a $\left.R_{\mathrm{s}}\left(Q_{\mathrm{f}}\left(R_{\mathrm{f}}\left(Q_{\mathrm{dl}} R_{\mathrm{ct}}\right)\right)\right)\right)$, b $R_{\mathrm{s}}\left(Q_{\mathrm{dl}}\left(R_{\mathrm{ct}} O\right)\right), \mathbf{c} R_{\mathrm{s}}\left(Q_{\mathrm{dl}} R_{\mathrm{ct}}\right)$

Table 4 Fitting results of EIS in the sterile soil solution

\begin{tabular}{|c|c|c|c|c|c|c|c|c|c|}
\hline Time (day) & $R_{\mathrm{s}}\left(\Omega \mathrm{cm}^{2}\right)$ & $Y_{\mathrm{f}}\left(\mathrm{S} \mathrm{s} \mathrm{s}^{n} / \mathrm{cm}^{2}\right)$ & $n_{\mathrm{f}}$ & $R_{\mathrm{f}}\left(\Omega \mathrm{cm}^{2}\right)$ & $Y_{\mathrm{dl}}\left(\mathrm{S} \mathrm{s}^{n} / \mathrm{cm}^{2}\right)$ & $n_{\mathrm{dl}}$ & $R_{\mathrm{ct}}\left(\Omega \mathrm{cm}^{2}\right)$ & $W\left(\mathrm{mS} \mathrm{s}^{5} / \mathrm{cm}^{2}\right)$ & $B\left(\mathrm{~s}^{5}\right)$ \\
\hline 0.25 & 218.4 & & & & 0.0005957 & 0.4836 & 4,287 & 4.739 & 15.05 \\
\hline 2 & 144.1 & 0.0002505 & 0.7701 & 2,967 & 0.0003582 & 0.3895 & 4,148 & & \\
\hline 5 & 193.2 & 0.0002197 & 0.8105 & 2,857 & 0.0009250 & 0.2983 & 4,078 & & \\
\hline 10 & 198.6 & 0.0002687 & 0.7812 & 12,010 & 0.0002710 & 0.4151 & 75,350 & & \\
\hline 30 & 210.7 & 0.0001095 & 0.8105 & 12,560 & 0.0001331 & 0.2479 & 76,340 & & \\
\hline 60 & 248.4 & 0.0002420 & 0.8940 & 13,000 & 0.0001255 & 0.2544 & 59,210 & & \\
\hline
\end{tabular}

$[26,37]$ and obstacle the migration of $\mathrm{SO}_{4}^{2-}$ and $\mathrm{Cl}^{-}$into the interface of metal. The live film with negative charges has a repulsion effect to corrosive anion and hence inhibits the corrosion process. However, at the later stage (from the 6th day on), the corrosion rate of the steel in the sterile soil solution decreases significantly and then remains stable, while in the SRB-inoculated soil solution, the corrosion rate continues to increase gradually and remains a high value. The results show that the activity of SRB accelerates corrosion rate of the steel at the later stage of the experiment.

It is generally recognized that the change of $E_{\text {corr }}$ and the corrosion rate is essentially derived from the alteration of the corrosion process [25]. To analyze the influence of SRB in corrosion reaction of the steel, $E_{\text {corr }}$ of the steel is shown in Fig. 9. In the first 3 days, the SRB number increases sharply due to the cellular exponential growth phase and keeps a large quantity in the next 15 days (Fig. 2). From the 2 nd day to the 20th day, due to the activity of SRB, both $E_{\text {corr }}$ and the corrosion rate increase over time, revealing the influence of SRB on the corrosion behavior of the steel. Then, $E_{\text {corr }}$ continues to increase slightly, while the corrosion rate decreases a little in the rest time of the experiment (Fig. 9). The facts demonstrate that, although the SRB number is limited and the influence of the activity 
Table 5 Fitting results of EIS in the inoculated soil solution

\begin{tabular}{lcllllll}
\hline Time (day) & $R_{\mathrm{s}}\left(\Omega \mathrm{cm}^{2}\right)$ & $Y_{\mathrm{f}}\left(\mathrm{S} \mathrm{s}^{n} / \mathrm{cm}^{2}\right)$ & $n_{\mathrm{f}}$ & $R_{\mathrm{f}}\left(\Omega \mathrm{cm}^{2}\right)$ & $Y_{\mathrm{dl}}\left(\mathrm{S} \mathrm{s}^{n} / \mathrm{cm}^{2}\right)$ & $n_{\mathrm{dl}}$ & $R_{\mathrm{ct}}\left(\Omega \mathrm{cm}^{2}\right)$ \\
\hline 0.25 & 278.4 & & & & 0.0003562 & 0.7593 \\
2 & 57.75 & 0.001158 & 0.799 & 8,989 & 0.09159 & 0.8772 \\
5 & 36.43 & 0.006222 & 0.8668 & 16.64 & 0.007715 & 0.9521 \\
10 & 28.87 & 0.005844 & 0.8846 & 10.03 & 0.009444 & 0.9456 \\
30 & 21.90 & 0.006233 & 0.8952 & 14.12 & 0.002679 & 12,704 \\
60 & 21.79 & 0.008475 & 0.9161 & 15.89 & 0.008074 & 0.9183 \\
\hline
\end{tabular}

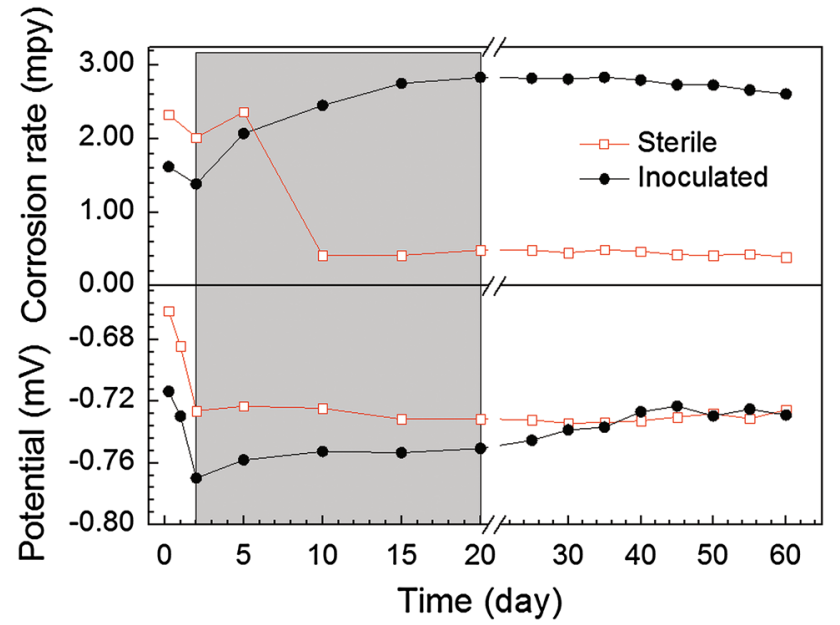

Fig. 9 Corrosion rate and open circuit potential of X80 pipeline steel as a function of time

of SRB can be ignored, the metabolite by SRB still remains and affects the corrosion behavior of the steel.

\section{Conclusions}

(1) Soil solution is more close to the complex soil environment around pipeline.

(2) Uniform corrosion is the main corrosion form of X80 steel in the sterile soil solution, while localized corrosion dominates in the SRB-inoculated soil solution.

(3) Corrosion of the steel is inhibited by the activity of SRB in the first 5 days and accelerated in the rest of this experiment. The activity of SRB leads to the shift of phase response to low frequency, the decrease of electrolyte resistance, and the alteration of dielectric constant of the film.

(4) Both the activity and metabolite of SRB have influence on the corrosion behavior of the steel.

Acknowledgments We are very grateful to the anonymous reviews and the editor for the instructive comments, which are invaluable for the quality improvement of the paper. The first author thanks Long Zhou for useful help in corrosion product analysis and Zhibin Shen for invaluable help in language polishing. We are grateful for financial support of the National Natural Science Foundation of China (Grant Nos. 51471176 and 51161001) and National RD Infrastructure and Facility Development Program of China (Grant No. 2005DKA10400CT-2-02).

\section{References}

[1] Z. Liu, C. Du, X. Zhang, F. Wang, X. Li, Acta Metall. (Engl. Lett.) 26, 489 (2013)

[2] T.Y. Jin, Z.Y. Liu, Y.F. Cheng, Int. J. Hydrog. Energy 35, 8014 (2010)

[3] M. Wu, X. Chen, C. He, J. Xiao, Acta Metall. Sin. (Engl. Lett.) 24, 65 (2011)

[4] M. Zhu, Z. Liu, C. Du, X. Li, J. Li, Q. Li, J. Jia, Acta Metall. Sin. 49, 1590 (2013). (in Chinese)

[5] R. Javaherdashti, Anti-Corros. Method. M. 46, 173 (1999)

[6] I.B. Beech, C.C. Gaylarde, Rev. Microbiol. 30, 177 (1999)

[7] E.S. Bastin, Bull. Am. Assoc. Petrol. Geol. 10, 1270 (1926)

[8] X.L. Wu, J.H. Liu, X.Y. Chen, Acta Metall. Sin. (Engl. Lett.) 12, 867 (1999)

[9] C.A.H. Von Wolzogen Kuhr, L.S. Van der Vlugt, Water (The hague) 18, 147 (1934)

[10] J.F.D. Stott, Corros. Sci. 35, 667 (1993)

[11] X.D. Zhao, J.Z. Duan, B.R. Hou, S.R. Wu, J. Mater. Sci. Technol. 23, 323 (2007)

[12] I.B. Beech, C.W.S. Cheung, Int. Biodeterior. Biodegrad. 35, 59 (1995)

[13] H. Venzlaff, D. Enning, J. Srinivasan, K.J.J. Mayrhofer, A.W. Hassel, F. Widdel, M. Stratmann, Corros. Sci. 66, 88 (2013)

[14] L. Yu, J. Duan, X. Du, Y. Huang, B. Hou, Electrochem. Commun. 26, 101 (2013)

[15] G. Reguera, K.D. McCarthy, T. Mehta, J.S. Nicoll, M.T. Tuominen, D.R. Lovley, Nature 435, 1098 (2005)

[16] J. Duan, S. Wu, X. Zhang, G. Huang, M. Du, B. Hou, Electrochim. Acta 54, 22 (2008)

[17] F.M. AlAbbas, C. Williamson, S.M. Bhola, J.R. Spear, D.L. Olson, B. Mishra, A.E. Kakpovbia, Int. Biodeterior. Biodegrad. 78, 34 (2013)

[18] B.J. Little, R. Ray, Corrosion 58, 424 (2002)

[19] S.E. Werner, C.A. Johnson, N.J. Laycock, P.T. Wilson, B.J. Webster, Corros. Sci. 40, 465 (1998)

[20] W.M. Dunne, Clin. Microbiol. Rev. 15, 155 (2002)

[21] R. Zuo, E. Kus, F. Mansfeld, T.K. Wood, Corros. Sci. 47, 279 (2005)

[22] C. Sun, J. Xu, F. Wang, Ind. Eng. Chem. Res. 50, 12797 (2011)

[23] J. Xu, K. Wang, C. Sun, F. Wang, X. Li, J. Yang, C. Yu, Corros. Sci. 53, 1554 (2011) 
[24] F. Kuang, J. Wang, L. Yan, D. Zhang, Electrochim. Acta 52, 6084 (2007)

[25] B.J. Little, J.S. Lee, R.I. Ray, Electrochim. Acta 54, 2 (2008)

[26] X. Sheng, Y.P. Ting, S.O. Pehkonen, Corros. Sci. 49, 2159 (2007)

[27] K.M. Ismail, A. Jayaraman, T.K. Wood, J.C. Earthman, Electrochim. Acta 44, 4685 (1999)

[28] V. Raman, S. Tamilselvi, N. Rajendran, Mater. Corros. 59, 329 (2008)

[29] S. Cheng, J. Tian, S. Chen, Y. Lei, X. Chang, T. Liu, Y. Yin, Mater. Sci. Eng. C 29, 751 (2009)

[30] Y. Wan, D. Zhang, H. Liu, Y. Li, B. Hou, Electrochim. Acta 55, $1528(2010)$
[31] B. Zheng, Y. Zhao, W. Xue, H. Liu, Surf. Coat. Technol. 216, 100 (2013)

[32] C. Sun, X.M. Li, J. Xu, M.C. Yan, F.H. Wang, Z.Y. Wang, Acta Phys-Chim. Sin. 28, 2659 (2012)

[33] L. Hao, S. Zhang, J. Dong, W. Ke, Corros. Sci. 58, 175 (2012)

[34] T.R. Jack, G.V. Boven, M. Wilmott, R.L. Sutherby, R.G. Worthinghan, Mater. Perform. 33, 17 (1994)

[35] R.P.V. Cruz, A. Nishikata, T. Tsuru, Corros. Sci. 38, 1397 (1996)

[36] T. Nishimura, Corros. Sci. 52, 3609 (2010)

[37] J.E.G. Gonzalez, F.J.H. Santana, J.C. Mirza-Rosca, Corros. Sci. 40, 2141 (1998) 